\title{
DESKRIPTIF TINGKAT KECEMASAN REMAJA PUTRI DALAM MENGHADAPI MENARCHE DI SMP MUHAMMADYAH PEKANBARU
}

\author{
Maswarni $^{[1]}$, Ira Wati $^{[2]}$ \\ [1] staff pengajar Jurusan D III Keperawatan \\ Fakultas MIPA dan Kesehatan Universitas Muhammadiyah Riau \\ Email : Maswarni82@yahoo.co.id[1] \\ [2] Alumnus Jurusan D III Keperawatan-FMIPA. UMRI
}

\begin{abstract}
Abstrak
Menarche adalah menstruasi pertama yang dialami oleh remaja pada saat pubertas. Biasanya ditandai adanya perubahan lain seperti pertumbuhan payudara, pertumbuhan rambut daerah pubis dan aksila, serta distribusi lemak pada daerah pinggul. Remaja putri yang mengalami menarche biasanya akan merasa cemas. Kecemasan adalah gangguan alam perasaan atau kekhawatiran yang mendalam dan berkelanjutan. Tujuan penelitian ini adalah untuk melihat gambaran tingkat kecemasan remaja putri dalam menghadapi Menarche di SMP Muhammadiyah Pekanbaru. Jenis penelitian ini adalah Deskriptif. Penelitian ini dilaksanakan pada tanggal 18 - 19 Mei 2010 di SMP Muhammadiyah Pekanbaru. Populasi Pada Penelitian ini adalah remaja putri yang ada di SMP Muhammadiyah Pekanbaru dengan jumlah sampel 43 responden dengan menggunakan teknik Stratifiet Random Sampling. Teknik pengumpulan data menggunakan kuesioner sebanyak 43 responden. Hasil penelitian menunjukkan bahwa gambaran tingkat kecemasan remaja putri dalam menghadapi Menarche di SMP Muhammadiyah Pekanbaru yaitu Kecemasan berat sebanyak 15 orang (34,88\%), Kecemasan sedang 11 orang (25,58\%), Kecemasan ringan sebanyak 9 orang (20,93\%), Tidak cemas sebanyak 8 orang (18,60\%), Kecemasan berat sekali tidak ada (0). Di harapkan remaja putri SMP Muhammadiyah Pekanbaru agar bisa mengatasi kecemasan pada saat meghadapi Menarche dengan cara berolah raga, mampu berpikir positif. Berdasarkan penelitian perlu adanya penyebarluasan informasi tentang Menarche agar remaja putri tidak mengalami kecemasan berat dalam menghadapi Menarche sehingga tingkat kecemasan remaja putri dalam menghadapi menarche dapat di minimalisir..
\end{abstract}

Kata Kunci : Tingkat kecemasan, Remaja Putri, Menarche

\section{PENDAHULUAN}

Kecemasan merupakan salah satu emosi yang paling menimbulkan stress yang dirasakan oleh banyak orang. Kecemasan juga disebut dengan ketakutan atau perasaan gugup, cemas, khawatir, bimbang, firasat buruk, takut akan pikirannya sendiri dan mudah tersinggung, merasa tegang, tidak tenang, gelisah, gerakan sering serba salah dan mudah terkejut, takut sendirian, takut keramaian dan banyak orang, gangguan pola tidur, mimpi-mimpi yang menegangkan, gangguan konsentrasi dan daya ingat, gangguan pencernaan, sakit kepala dan lain sebagainya (Hawari, 2001).
Di Inggris, rata-rata haid pertama datang pada usia 13 tahun. Dibandingkan dengan keadaan abad yang lalu, dimana haid petama pada umumnya datang pada umur 15 tahun. Nampaknya anak-anak gadis dari orang tua yang lebih berada, mengalami Menarche lebih cepat dari pada mereka yang mempunyai orang tua yang kurang berada. Tetapi rata-rata tidak lebih dari 6 sampai 9 bulan. Kedatangan haid pertama tergantung pada tingkat sosial ekonomi dari pada iklim tempat tinggal. (Llewellyn, 2005 ).

Di Indonesia, Statistik tentang perasaan para remaja putri saat menghadapi Menarche di dapatkan 77 persen mereka mengalami 
kecemasan, 24 persen mereka tidak peduli, 15 persen mereka di landa kebingungan, 12 persen mereka merasa sedih, dan 6 persen merasa bangga pada dirinya sendiri ( Ridha, $2006)$..

\section{METODOLOGI PENELITIAN}

Dalam penelitian ini peneliti menggunakan jenis penelitian deskriptif. Menurut Fathoni (2006), deskripstif adalah suatu penelitian yang bermaksud mengadakan pemeriksaan dan pengukuran. Pengukuran terhadap gejala tertentu, adapun peneliti mengajukan pertanyaan mengenai tingkat kecemasan remaja putri dalam menghadapi menarche di SMP Muhammadiyah Pekanbaru.

Dalam analisa data peneliti menggunakan tingkat kecemasan sebagai alat ukur dengan hasil :
1. Tidak cemas
$: 0-14$
2. Kecemasan Ringan
$: 14-20$
3. Kecemasan Sedang
: $21-27$
4. Kecemasan Berat
$: 28-41$
5. Kecemasan Berat Sekali : $42-56$

\section{HASIL DAN PEMBAHASAN}

Berdasarkan hasil penelitian yang dilakukan pada tanggal 18- 19 Mei 2010 terhadap 43 responden dengan menggunakan alat ukur kuesioner tentang gambaran tingkat kecemasan remaja putri dalam menghadapi menarche di SMP Muhammadiyah Pekanbaru dapat dilihat pada tabel-tabel sebagai berikut :

Tabel 1. Distribusi Frekuensi Umur

Responden Di SMP Muhammadiyah Pekanbaru Mei 2010

\begin{tabular}{|c|c|c|c|}
\hline No & Umur & $\begin{array}{c}\text { Frekuensi } \\
(\mathbf{f})\end{array}$ & $\begin{array}{c}\text { Persentase } \\
(\mathbf{\%})\end{array}$ \\
\hline 1 & 12 tahun & 19 & 44,1 \\
2 & 13 tahun & 15 & 34,88 \\
3 & 14 tahun & 9 & 20,93 \\
\hline & Jumlah & $\mathbf{4 3}$ & $\mathbf{1 0 0}$ \\
\hline
\end{tabular}

Menurut pendapat Santrolk (2003) menyebutkan bahwa remaja awal yang menghadapi menarche akan terasa cemas, yang berpengaruh pada reaksi emosional pada berbagai kekhawatiran pada perubahan yang terjadi pada dirinya. Penelitian ini sesuai dengan hasil penelitian Yuslina (2009) dengan hasil penelitian yaitu 75 Persen remaja putri yang mengalami kecemasan berat rata-rata pada umur 12 tahun dan 25 persen adalah rata-rata umur 13 dan 14.

Tabel 2. Distribusi Frekuensi Responden Terhadap InformasiTentang Menarche di SMP Muhammadiyah PekanbaruMei 2010

\begin{tabular}{|c|l|c|c|}
\hline No & $\begin{array}{c}\text { Mendapatkan } \\
\text { Informasi }\end{array}$ & $\begin{array}{c}\text { Frek } \\
\text { (f) }\end{array}$ & $\begin{array}{c}\text { Persentase } \\
(\boldsymbol{\%})\end{array}$ \\
\hline 1 & Pernah & 15 & 34,88 \\
2 & Tidak pernah & 28 & 65,11 \\
\hline & Jumlah & $\mathbf{4 3}$ & $\mathbf{1 0 0}$ \\
\hline
\end{tabular}

Menurut (Caroline, 2001) Hubungan kurangnya informasi tentang menarche dengan kecemasan remaja putri dapat berdampak terhadap reaksi individual, dimana remaja putri yang tidak pernah mendapatkan informasi tentang menarche pada saat menghadapi menarche akan mengalami kecemasan seperti depresi, rasa takut, gangguan konsentrasi, mudah tersinggung, gelisah, susah tidur, sakit kepala. Sedangkan remaja putri yang pernah mendapat informasi tentang menarche pada saat menghadapi menarche akan lebih tenang dan tidak gelisah dan telah mampu menentukan sikapnya, bahwa dirinya telah tumbuh dewasa.

Tabel 3. Distribusi Frekuensi Gambaran
Tingkat Kecemasan Remaja Putri dalam
Menghadapi Menarche di SMP
Muhammadiyah Pekanbaru Mei 2010
\begin{tabular}{|c|c|c|c|}
\hline No & Tingkat \\
& Kecemasan & Frekuensi & $\begin{array}{c}\text { Persentase } \\
(\%)\end{array}$ \\
\hline
\end{tabular} 


\begin{tabular}{|l|l|c|c|}
\hline 1 & Tidak Cemas & 8 & 18,60 \\
2 & Ringan & 9 & 20,94 \\
3 & Sedang & 11 & 25,58 \\
4 & Berat & 15 & 34.88 \\
5 & Berat Sekali & 0 & 0 \\
\hline \multicolumn{2}{|r|}{ Jumlah } & $\mathbf{4 3}$ & $\mathbf{1 0 0}$ \\
\hline
\end{tabular}

Tingkat kecemasan remaja putri berat dikarenakan oleh beberapa faktor yaitu umur, kurangnya informasi yang benar tentang menarche dari tenaga kesehatan dan kurangnya kepedulian dari keluarga atau orang tua terhadap perubahan yang terjadi pada putrinya sehingga menimbulkan kondisi emosional yang tidak menyenangkan pada remaja putri, yang di tandai oleh perasaan - perasaan seperti ketegangan, ketakutan, dan rasa khawatir dalam menghadapi menarche. Dari uraian diatas maka pentingnya informasi yang benar tentang menarche pada remaja putri sehingga remaja putri dapat bersikap baik dan benar dan tahu apa yang akan dia lakukan pada saat mengalami menarche.

\section{DAFTAR PUSTAKA}

Ahmad, A.K.(2003). Kamus Lengkap Kedokteran, Edisi Revisi. Surabaya : Gitamedia Pers

August, dkk. (2000). Pemberdayaan Wanita dalam Bidang Kesehatan. Jakarta : EGC

Caroline.(2001). Sindrom Pramenstruasi Anak. Jakarta : Penerbit Umum

Erna. (2005). Panduan Kesehatan Reproduksi Wanita. Jakarta : SKP

Fitri.R.(2009). Kesehatan Wanita.Jakarta : Restu Agung.

Froggatt. (2003). Panduan Mengatasi Kecemasan . Jakarta : EGC

Harry.(2006). Kecemasan Remaja Putri. Diperoleh tanggal 14 Oktober 2009 dari http://www.medicastor.com

Hanito. (2004). Dasar Keperawatan Maternitas. Jakarta: GGS

Haggai. (2004). Bagaimana cara Mengatasi Kecemasan. Batam Centre: Gospel Press
Hawari, D.(2001). Manejemen Stress, Cemas dan Depresi. Jakarta : Fakultas Kedokteran, Universitas Indonesia

-------, D.(2004). Ilmu Kedokteran Jiwa dan Kesehatan Jiwa. Jakarta : Dana bhakti primayasa

Helen. (2007). Faktor - faktor Pemicu Kecemasan Siswa. Diperoleh tanggal 17 Oktober 2009 dari http://www.tupays.com

Hendra, T. (2003). Kamus Kedokteran. cef : 25. Jakarta : Jembatan

Hendra. (2000). Perasaan Cemas dan Depresi. Yogyakarta : Dive Press Group

Hendrik. (2006). Problema Haid. Solo : Tiga Serangkai

Hewelly. (2006). Panduan Terlengkap tentang Kesehatan setiap Wanita. Jakarta : Delapiatasa

Maulana, M. (2008). Cara menjaga kebugaran tubuh. Jakarta : Katahati

Notoatmodjo, S.(2003). Ilmu Kesehatan Masyarakat. Jakarta : Ardi maha satya

----------, S.(2005). Metode Penelitian Kesehatan. Jakarta : Rineka Cipta

Ridha, A. (2006). Manejemen Pubertas. Bandung : Syamsil Cipta

Roesli,V. (2001). Petunjuk untuk tenaga kesehatan. Jakarta : Gramedia

Santrolk, J.H. (2003). Perkembangan Remaja. Edisi VI. Jakarta : Erlangga

Stuart,G.W. (2006). Buku Saku Keperawatan Jiwa. Jakarta : EGC

Sarwono. (2005). Haid pertama pada remaja putri . Diperoleh tanggal 19 Oktober 2009 dari http://www.mediskator.com

Winiasti. dkk. (2002). Pengalaman Materi Membantu Remaja Mengatasi Dirinya. Jakarta : BKKBN

Winksosastro.(2007). Ilmu Kandungan. Jakarta : YGPSP

Woston. (2000). Penagaruh Media Massa Terhadap Tingkah Laku. Di peroleh pada tanggal 12 Juli 2009 Dari http://www.publitbang.co.id

Yuslina. (2009). Penelitian Kecemasan Remaja Putri menghadapi menarche. Di peroleh pada tanggal 20 Juli 2010 Dari http://wwww.medicastor.co.id 